\title{
Ameloblastic Fibroma
}

\author{
Brenda L. Nelson • Gretchen S. Folk
}

Received: 6 October 2008/Accepted: 9 October 2008/Published online: 31 October 2008

(C) The Author(s) 2008. This article is published with open access at Springerlink.com

\section{History}

An 18-year-old male presented for a routine dental examination with an incidental finding in the left posterior maxilla.

\section{Radiographic Features}

Imaging studies revealed a well-circumscribed, unilocular radiolucency preventing eruption of the left maxillary second molar and displacing it in a superior and posterior direction, into the maxillary sinus (Fig. 1).

\section{Treatment}

The area was treated with thorough curettage and the associated maxillary second molar was extracted.

\section{Diagnosis}

Histological evaluation revealed multiple fragments of richly cellular mesenchymal tissue containing round drop-

The opinions and assertions expressed herein are those of the author and are not to be construed as official or representing the views of the Department of the Navy or the Department of Defense.

B. L. Nelson $(\bowtie) \cdot$ G. S. Folk

Department of Anatomic Pathology, Naval Medical Center,

San Diego, 34800 Bob Wilson Drive, San Diego,

CA 92134-5000, USA

e-mail: Brenda.nelson@med.navy.mil

B. L. Nelson · G. S. Folk

Scripps Oral Pathology Service, San Diego, CA, USA like islands and long narrow anastomosing cords of odontogenic epithelium. The epithelial islands and cords were characterized by peripheral columnar or cuboidal hyperchromatic cells and were frequently only two cell layers thick (Fig. 2). The mesenchymal component contained evenly distributed plump ovoid and stellate cells in a loose myxoid to predominantly eosinophilic matrix, resembling the primitive dental papilla. Mitotic activity was not appreciated.

\section{Discussion}

Ameloblastic fibromas are neoplasms of odontogenic epithelium and mesenchymal tissues, and as such are categorized as mixed odontogenic tumors. Other mixed odontogenic lesions, such as ameloblastic fibro-odontomas and odontomas share some clinical, radiographic and histologic similarities with ameloblastic fibroma. In the past, it was suggested that these lesions represented a spectrum of a single entity, with ameloblastic fibromas, the least differentiated of the tumors, maturing and developing into ameloblastic fibro-odontomas and later odontomas [1]. This theory has been refuted with the support of the tumors' associated demographics. The least differentiated lesion, ameloblastic fibroma, actually occurs, on average, at an older age then the more differentiated ameloblastic fibro-odontoma and odontoma [4]. Further more, ameloblastic fibro-odontomas and odontomas are better categorized as hamartomas and as a result, unlike the ameloblastic fibroma, have little chance of recurrence or malignant transformation [4]. For these reasons, despite many similarities, it is essential to differentiate the ameloblastic fibroma from other mixed odontogenic lesions because it has true neoplastic qualities. 


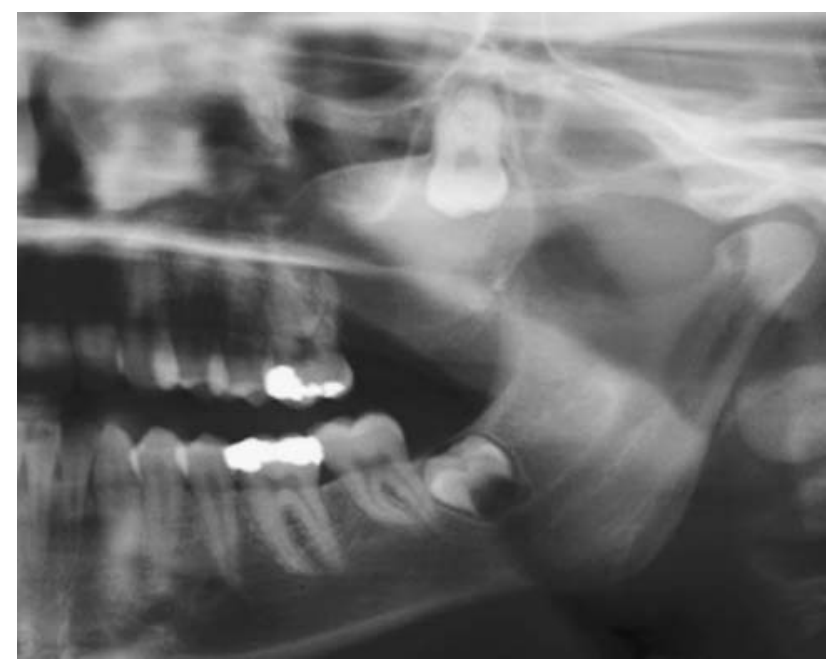

Fig. 1 Well-defined unilocular radiolucency prohibiting the eruption of the left maxillary second molar

Ameloblastic fibromas are rare and comprise approximately $2 \%$ of odontogenic tumors [2,3]. The tumors are considered a tumor of childhood and adolescence and occur almost exclusively in the first and second decades of life [3, 4]. A slight male predilection has been noted $[4,5]$. The most common location for the tumor is the posterior mandible, followed by the posterior maxilla. Patients often present with painless swelling of the jaw and the lesion may affect the normal eruption of teeth in the area. An impacted tooth may be associated with the tumor in approximately three quarters of the cases [2, 5, 6]. Some lesions are asymptomatic, with up to $20 \%$ of cases initially detected upon review of routine dental radiographs $[1,3,4,6]$.

Radiographically, ameloblastic fibromas are unilocular lesions, occasionally multilocular when larger, with smooth well-demarcated borders. Cortical expansion may or may not be discernable on plane film. Because lesions are frequently associated with unerupted teeth they may initially be interpreted as dentigerous cysts $[1,3,4,7]$.

Grossly, ameloblastic fibroma appears as firm, lobular soft tissue mass with a smooth surface [3]. If a tooth is associated with the lesion it may accompany the specimen. A capsule is generally not appreciated. Microscopically, an ameloblastic fibroma is composed of a connective tissue background that appears to recapitulate dental papilla, resembling stellate reticulum $[1,3,7]$. This tissue is composed of spindled and angular cells with little collagen, imparting a myxomatous appearance. The epithelial component is made up of thin branching cords or small nests of odontogenic epithelium with little cytoplasm and basophilic nuclei. Larger nests may show a central area of stellate reticulum. Mitoses should not be a feature of ameloblastic fibroma $[1,3]$. The presence of mitosis should expand the

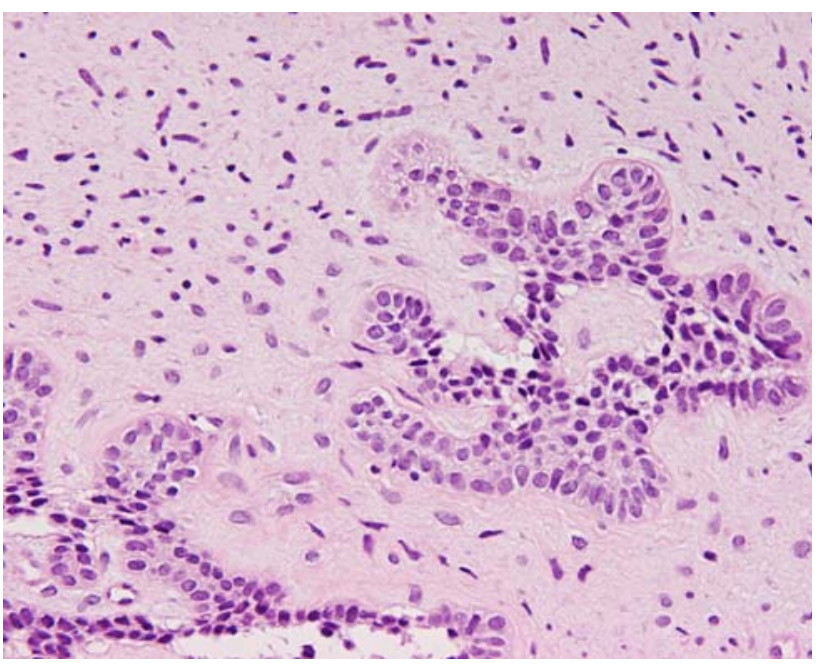

Fig. 2 Round islands and narrow cords of odontogenic epithelium in a cellular, primitive mesenchymal background

differential diagnosis to include malignant entities, to include ameloblastic fibrosarcoma. Finally, immunohistochemistry generally does not aid in differentiating ameloblastic fibroma from other mixed odontogenic tumors.

Surgical excision or thorough curettage with removal of affected teeth is the treatment of choice $[1,2]$. The recurrence rate varies among sources, but is considered to be low $[5,7]$. While uncommon, the possibility of malignant transformation of ameloblastic fibroma into ameloblastic fibrosarcoma is well documented $[8,9]$.

Open Access This article is distributed under the terms of the Creative Commons Attribution Noncommercial License which permits any noncommercial use, distribution, and reproduction in any medium, provided the original author(s) and source are credited.

\section{References}

1. Tomich CE. Benign mixed odontogenic tumors. Semin Diagn Pathol. 1999;16:308-16.

2. Regezi JA, Kerr DA, Courtney RM. Odontogenic tumors: analysis of 706 cases. Oral Surg. 1978;36:771-8.

3. Cohen DM, Bhattacharyya I. Ameloblastic fibroma, ameloblastic fibro-odontoma, and odontoma. Oral Maxillofac Surg Clin North Am. 2004; 16:375-84.

4. Slootweg PJ. An analysis of the interrelationship of mixed odontogenic tumors-ameloblastic fibroma, ameloblastic fibroodontoma, and the odontomas. Oral Surg Oral Med Oral Pathol. 1981;51:266-76.

5. Philipsen HP, Reichart RP, Pratorius F. Mixed odontogenic tumors and odontomas: considerations on interrelationship. Review of the literature and presentation of 134 new cases of odontomas. Oral Oncol. 1997;33:86-99.

6. Trodahl JN. Ameloblastic fibroma. A survey of cases from the armed Forces Institute of Pathology. Oral Surg Oral Med Oral Pathol. 1972;33:547-58. 
7. Hansen LS, Ficarra G. Mixed Odontogenic tumors: an analysis of 23 new cases. Head Neck Surg. 1988;10:330-43.

8. Leider AS, Nelson JF, Trodahl JN. Ameloblastic fibroma. Oral Surg. 1972;33:559-69.
9. Altini M, Thompson SH, Lownie JF, Berezowski BB. Ameloblastic sarcoma of the mandible. J Oral Maxillofac Surg. 1985;43:789-94. 